\title{
Site Selection by Hynobius tokyoensis for Breeding in a Stream
}

\author{
SADAO IHARA \\ Department of Biology, Ohu University, 31-1 Misumido, Tomita, Koriyama, Fukushima \\ 963-8611, JAPAN
}

\begin{abstract}
A breeding site of the salamander Hynobius tokyoensis in a flowing stream was surveyed in the Yamanaka District of Miura Peninsula, central Japan, from March to April 2000, and from February to March 2002. The numbers of males, females, and egg sac pairs found in the stream were 32, three, and 31 in 2000, and 27, three, and 32 in 2002, respectively. The results of field observations suggest that the salamander prefers hollows under broader stones in the stream for breeding and/or spawning, presumably in order to avoid accidental washing away of egg sacs.
\end{abstract}

Key words: Salamander, Hynobius tokyoensis, Breeding site selection, Running water

\section{INTRODUCTION}

The jelly surrounding amphibian eggs is highly susceptible to desiccation, freezing, and high temperature, so the survival rate of the eggs is directly influenced by changes in the conditions of their surroundings (Duellman and Trueb, 1986). Several species of frogs and salamanders have been shown to select spawning sites suitable for optimal development of their eggs and for minimization of the risk of egg loss (Duellman and Trueb, 1986; Stebbins and Cohen, 1995).

In the Asiatic hynobiid salamanders, environmental properties of spawning sites differ among the species (Sato, 1943), but data on the environmental factors governing the spawning site selection are available for only one species, Hynobius nebulosus, which uses deep

Tel: +81-24-932-9128; Fax: +81-24-933-7372

E-mail address: ihara66@aol.com cavities under water as sites for both mating and spawning (Tanaka, 1992). Moreover, the proximal causes for such site selection have never been investigated.

Of the Asiatic hynobiid salamanders, $H$. retardatus and $H$. nigrescens exhibit a common feature in the breeding site environment: at their breeding sites, the water temperature is more stable than adjacent portions of same water body and seldom drops low enough to freeze the eggs (Sato, 1989; Akita, 2000). It is therefore probable that in these and other hynobiid salamanders, the major significance of the spawning site selection lies in the minimization of egg mortality.

I have investigated the breeding environment favored by $H$. tokyoensis in the light of avoidance of egg loss. This salamander is distributed in hilly areas of the Kanto District and Fukushima Prefecture, and usually breeds in early spring in ponds, puddles, paddy fields, roadside gutters, and small mountain streams 
(Sato, 1943; Kusano and Miyashita, 1984; Kakegawa et al., 1989; Kusano and Kawakami, 1999). The egg sacs of $H$. tokyoensis are usually attached to twigs, litter, and logs in still water (Kusano and Kawakami, 1999), and under stones in running water (Kakegawa et al., 1989).

In stream breeding, the washing away of eggs may constitute a major cause of egg mortality. This may possibly be a reason why stream breeding salamanders generally attach their eggs beneath stones (Kakegawa et al., 1989; Petranka, 1998), because such sites may help prevent the eggs from being washed away. However, how stones are selected for breeding, and what effects this selection actually has on the protection of eggs, have remained unexamined.

\section{METHODS}

\section{Study site}

The study site was located at Yamanaka $\left(35^{\circ} 17^{\prime} \mathrm{N}, 139^{\circ} 38^{\prime} \mathrm{E}\right)$, Yokosuka City, Kanagawa Prefecture, approximately $30 \mathrm{~km}$ southwest of Metropolitan Tokyo. This area, comprising a small hill (110 m asl) with three small streams, is a well-known habitat of $H$. tokyoensis (Shibata, 1973; Kaneda and Ohno, 1998). Field observations were done in the smallest valley, which has a short first-order stream: the distance from the stream head to the confluence with a second-order stream was approximately $40 \mathrm{~m}$. The stream was shaded by broad-leaved trees, and its bed followed a moderate gradient with bedrock exposed in places and a number of scattered stones that are larger than fist size.

The amount of litter, dead branches, and mud accumulated in the stream channel was very small in 2000 . In 2002 , however, a portion of the channel was covered by mud that had been washed down from the hill. Some of the stones in the channel observed in 2000 were thus buried in the mud in 2002 .

The width of the channel ranged 1-2 m. During the winter season, the stream was greatly reduced in width and partially exposed due to low precipitation. Nevertheless, holes under cascades and hollows under stones were still filled with water. In spring, the running water body expanded over the channel due to an increase in precipitation, and this state continued until the next winter drought. The width of this stream, therefore, greatly varied annually, from 40 to $200 \mathrm{~cm}$.

\section{The numbers of individuals and deposited egg sacs}

Field surveys were made over five days between 2 March and 6 April 2000, and over 33 days between 16 February and 28 March 2002. Individuals and egg sacs beneath the stones were searched for and counted. Points at which the individuals were captured and locations at which the egg sacs were found in the stream were recorded every day during the study. Positions of stones to which the eggs were attached were recorded on simple diagrams to avoid double counting. Captured individuals were marked by toe clipping for identification and were released.

\section{Microenvironments of spawning sites and sites for males}

Microenvironments were compared between sites with and without males, and also between sites with and without egg sacs. During the preliminary field observations conducted in the spring of 1998 and 1999, both males and egg sacs were usually found in hollows formed between undersides of the stones and the streambed. In this study, therefore, I measured the area of the underside of each movable stone larger than $150 \mathrm{~mm}$ in length covering a hollow on the streambed, on 8 March 2000, and 16 February 2002. When two stones were stuck together, they were treated as a single stone. For expediency, each was estimated as a quadrilateral area using the longest length and width of the stones as seen from above. I also measured the water depth in the hollows under these stones on 8 and 16 March 2000 and 16 February 2002, and the velocity of the water running around each of the stones on 16 February and 27 and 28 March 2002. 
When the water depth in the hollow was first measured on 8 March 2000, there was no running water in the stream channel, but each hollow still had water, enabling me to take its depth. At each site, the stone was removed, and the depth was measured at the deepest part of the hollow. The stone was then carefully replaced immediately.

The velocity of water was quantified by measuring the time needed for a styrofoam ball ( $5 \mathrm{~mm}$ in diameter) to be carried from the upstream edge to the downstream edge of the stone. If currents measured on each side of a stone differed, the faster value was adopted. Because of the rainfall from the evening of 27 to the morning of $28 \mathrm{March}$, the water level of the stream was slightly higher on the second day.

\section{Stone size selection by salamanders}

Bootstrap sampling (Manly, 1997) of 10000 replications was used. The mean of the underside areas was consistently greater, though not statistically significant, for stones with egg sacs than for those with males. Therefore, data for the underside areas of stones, and the numbers of stones with and without egg sacs in each year, were subjected to this analysis.

The number of egg sacs washed away from original spawning sites

To determine the exact number of egg sacs naturally washed away by the running water, the number of egg sacs accidentally removed from the stones at the time of their measurements was excluded from that of egg sacs lost during the study period. The number of egg sacs was counted every day during the study period in 2002 .

\section{Territoriality of males}

The numbers of stones with no males, a single male, and more than one male underneath were counted and their ratios $(\%)$ were calculated for each observation day. These values were then compared with values expected on the basis of probability of binominal distributions. This was to estimate the degree of agonistic interaction (Umesao, 1949). The probability of binominal distributions was calculated following:

$$
\mathrm{P}(\mathrm{x})={ }_{\mathrm{N}} \mathrm{C}_{\mathrm{i}} \cdot \mathrm{p}^{\mathrm{i}} \cdot(1-\mathrm{p})^{\mathrm{N}-\mathrm{i}}
$$

where $N$ is the number of males hiding under a stone per day, $i$ is the expected number of males hiding under the stone, and $p$ is the probability of a male hiding under a particular stone.

\section{RESUlTS}

The number of individuals and egg sacs found

The area and depth were measured for 71 sites in 2000 , and 55 in 2002. A total of 32 males were found under 24 stones in 2000 , and 27 males under 17 stones in 2002 . The number of females found in each year was no more than three: these were found under three separate stones in both years. A total of 62 egg sacs (31 pairs) were found under 14 stones in 2000, and 64 egg sacs (32 pairs) under 14 stones in 2002 (Fig. 1). These egg sacs were attached to the undersides of stones that covered hollows, or to the surfaces of exposed bedrock on the floor of hollows, or to the surfaces of small stones and twigs within hollows (Fig. 2).

\section{Features of hollows used for breeding}

The underside areas of stones in the stream had a range of $180-3570 \mathrm{~cm}^{2}(\overline{\mathrm{x}}+\mathrm{SD}=1039.2 \pm$ $780.9, \mathrm{n}=71$ ) in 2000 , and $192-3570 \mathrm{~cm}^{2}$ $(\overline{\mathrm{x}}+\mathrm{SD}=1002.4 \pm 885.9, \mathrm{n}=55)$ in 2002. Areas of stones with males had a range of 216$3570 \mathrm{~cm}^{2}(\overline{\mathrm{x}}+\mathrm{SD}=1309.0 \pm 903.0, \mathrm{n}=24)$ in 2000 , and $210-3570 \mathrm{~cm}^{2}(\overline{\mathrm{x}}+\mathrm{SD}=1480.0 \pm 998.6, \mathrm{n}=$ 17 ) in 2002, and those of stones with egg sacs had a range of $400-3570 \mathrm{~cm}^{2}(\overline{\mathrm{x}} \pm \mathrm{SD}=1771.5 \pm$ $976.0, \mathrm{n}=14)$ in 2000 , and $210-3570 \mathrm{~cm}^{2}$ $(\overline{\mathrm{x}}+\mathrm{SD}=1554.2 \pm 1192.6, \mathrm{n}=14)$ in 2002 (Fig. 3). There was no significant difference in this measurement between stones with males in 2000 and 2002 (U-test, $z=-0.61, P>0.5$ ); nor between stones with egg sacs in 2000 and 2002 (U-test, $\mathrm{z}=0.73, \mathrm{P}>0.1$ ). The underside areas 


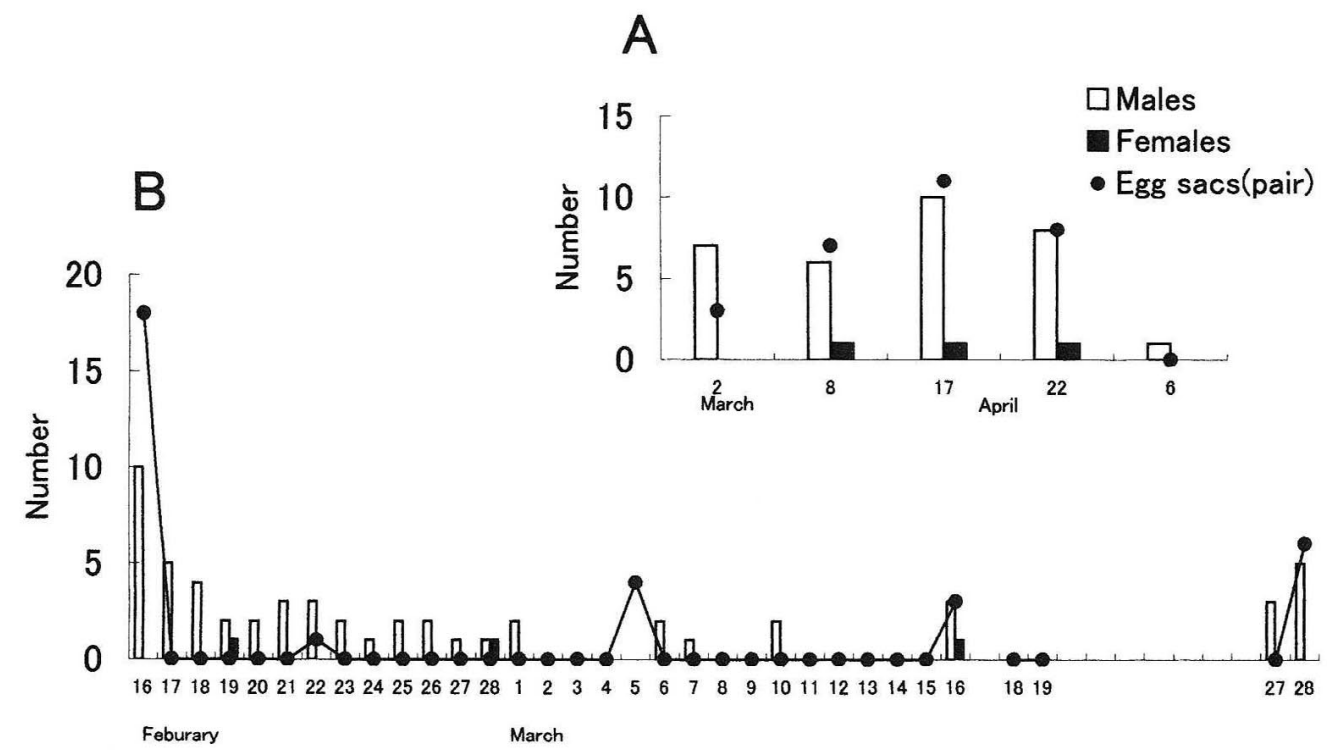

FIG. 1. The numbers of newly found individuals and egg sacs of Hynobius tokyoensis during the study periods in 2000 (A) and 2002 (B).

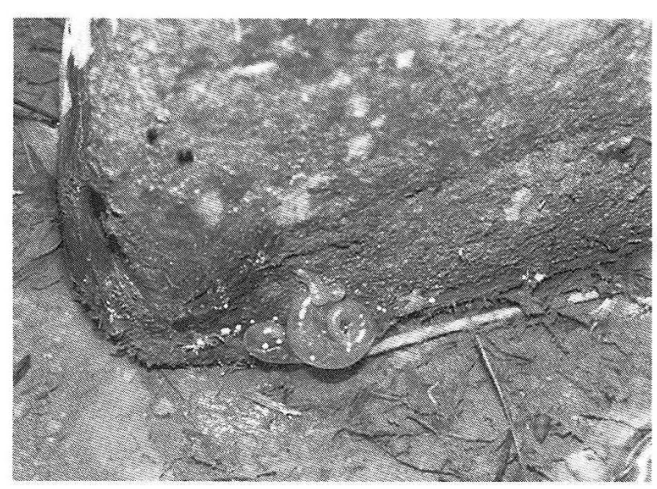

FIG. 2. Egg sacs of Hynobius tokyoensis attached to the underside of a stone.

of stones with males were significantly broader than those of stones without males in both years (U-test: $\mathrm{z}=1.83, \mathrm{P}<0.05$ in $2000 ; \mathrm{z}=2.70$, $\mathrm{P}<0.01$ in 2002). Likewise, underside areas of stones with egg sacs were significantly broader than those of stones without egg sacs in both 2000 (U-test: $\mathrm{z}=3.84, \mathrm{P}<0.01$ ) and 2002 $(\mathrm{z}=3.13, \mathrm{P}<0.01)$. In contrast, there were no significant differences in the area between stones with egg sacs and those with males (U-test: $\mathrm{z}=-1.61, \mathrm{P}>0.05$ in $2000 ; \mathrm{z}=0.44$, $P>0.05$ in 2002), although the mean of areas of stones with egg sacs was consistently greater than that of stones with males.

Larger stones were used by males in both years with significantly higher frequency (Spearman rank correlation coefficient test, $\mathrm{r}_{\mathrm{s}}=0.58, \mathrm{P}<0.01, \mathrm{n}=24$ in $2000 ; \mathrm{r}_{\mathrm{s}}=0.61$, $\mathrm{P}<0.05, \mathrm{n}=17$ in 2002). However, male body size (SVL) did not correlate with the area $\left(\mathrm{r}^{2}=0.18, \mathrm{P}>0.1, \mathrm{n}=32\right.$ in $2000 ; \mathrm{r}^{2}=0.21$, $\mathrm{P}>0.1, \mathrm{n}=27$ in 2002). The number of egg sacs deposited in each hollow was marginally significantly correlated with the underside area of the stone in $2000\left(\mathrm{r}^{2}=0.47, \mathrm{P}=0.05, \mathrm{n}=14\right)$, but not in $2002\left(\mathrm{r}^{2}=0.23, \mathrm{P}>0.1, \mathrm{n}=14\right)$.

The water depth in the hollows had a range of $0.0-6.0 \mathrm{~cm}(\overline{\mathrm{x}}+\mathrm{SD}=1.2 \pm 1.4, \mathrm{n}=71)$ on 8 March 2000, 0.0-6.0 cm ( $\overline{\mathrm{x}}+\mathrm{SD}=1.8 \pm 1.6, \mathrm{n}=71)$ on 16 March 2000 , and $0.0-6.5 \mathrm{~cm}(\overline{\mathrm{x}} \pm \mathrm{SD}=$ $1.53 \pm 1.1, \mathrm{n}=55$ ) on 16 February 2002. The depth of the hollows with males had a range of $0.0-5.0 \mathrm{~cm}(\overline{\mathrm{x}}+\mathrm{SD}=2.6 \pm 2.1, \mathrm{n}=6)$ on $8 \mathrm{March}$ $2000,1.5-6.0 \mathrm{~cm}(\overline{\mathrm{x}}+\mathrm{SD}=3.2 \pm 1.8, \mathrm{n}=11)$ on 17 March 2000, and $0.0-4.0 \mathrm{~cm}(\overline{\mathrm{x}}+\mathrm{SD}=2.4 \pm 0.7$, $\mathrm{n}=9$ ) on 16 February 2002; the depth of the hollow with egg sacs had a range of $0.0-5.0 \mathrm{~cm}$ $(\overline{\mathrm{x}}+\mathrm{SD}=3.0 \pm 2.1, \mathrm{n}=5)$ on 8 March $2000,1.0$ $6.0 \mathrm{~cm}(\overline{\mathrm{x}} \pm \mathrm{SD}=3.4 \pm 1.7, \mathrm{n}=8)$ on 17 March 

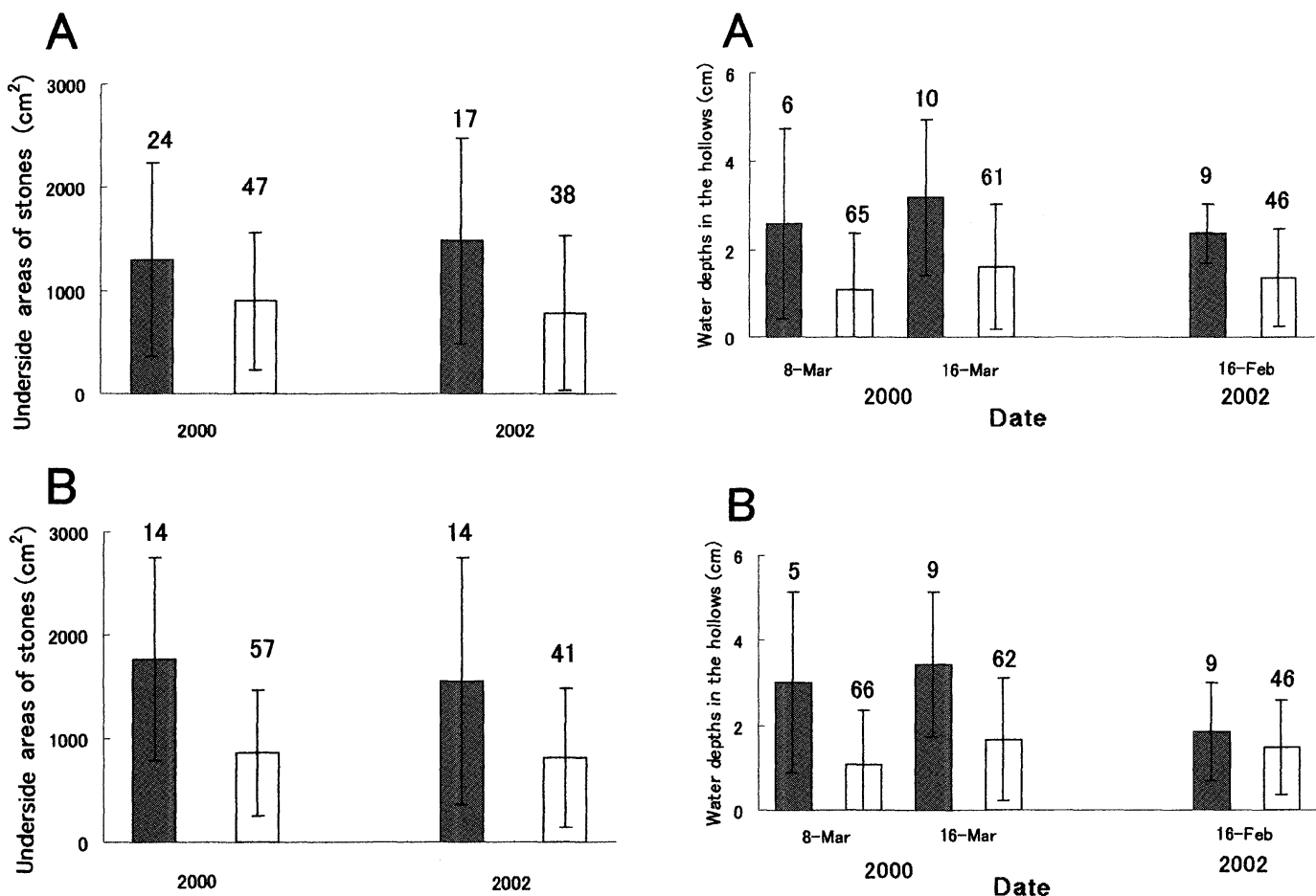

FIG. 3. Mean underside areas of stones with (filled squares) and without (open squares) males (A) and egg sac pairs (B). Vertical bars indicate ranges of standard deviations from means. Numerals above bars denote sample size.

2000 , and $0.0-4.0 \mathrm{~cm}(\overline{\mathrm{x}}+\mathrm{SD}=1.3 \pm 1.1, \mathrm{n}=9)$ on 16 February 2002 (Fig. 4).

Water depths of hollows with males were consistently significantly greater than those of hollows without males (U-test: $z=1.76$, $\mathrm{P}<0.05$, on 8 March 2000; $\mathrm{z}=3.22, \mathrm{P}<0.01$ on 17 March $2000 ; \mathrm{z}=3.34, \mathrm{P}<0.01$ on 16 February 2002). Likewise, the depths of hollows with egg sacs were consistently significantly greater than those of the hollows without egg sacs (U-test: $\mathrm{z}=2.05, \mathrm{P}<0.01$ on 8 March 2000; $\mathrm{z}=2.82, \mathrm{P}<0.01$ on 17 March 2000; $z=2.06, P<0.05$ on 16 February 2002).

The velocity of running water around the stones had a range of $0.0-4.0 \mathrm{~cm} / \mathrm{sec}(\overline{\mathrm{x}} \pm \mathrm{SD}=$ $0.09 \pm 0.92, \mathrm{n}=55$ ) on 16 February, $0.0-6.0 \mathrm{~cm} /$ $\sec (\overline{\mathrm{x}}+\mathrm{SD}=1.62 \pm 1.20, \mathrm{n}=55)$ on 27 March, and $9.0-30.0 \mathrm{~cm} / \mathrm{sec}(\overline{\mathrm{x}}+\mathrm{SD}=17.33 \pm 5.53, \mathrm{n}=55)$ on 28 March 2002 . The water velocity around

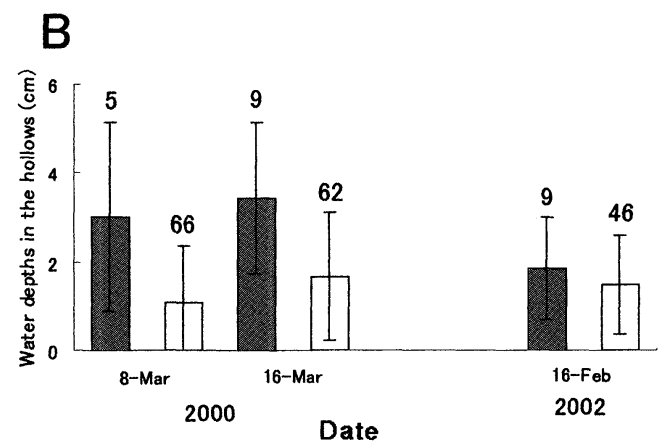

FIG. 4. Mean water depths of hollows with (filled squares) and without (open squares) males (A) and egg sac pairs (B). Vertical bars indicate ranges of standard deviations from means. Numerals above bars denote sample size.

stones with males had a range of $0.0-4.0 \mathrm{~cm}$ / $\sec (\overline{\mathrm{x}} \pm \mathrm{SD}=1.22 \pm 1.20, \mathrm{n}=9)$ on 16 February, $1.0-3.0 \mathrm{~cm} / \mathrm{sec}(\overline{\mathrm{x}}+\mathrm{SD}=1.83 \pm 1.04, \mathrm{n}=3)$ on $27 \mathrm{March}$, and $10.0-30.0 \mathrm{~cm} / \mathrm{sec}(\overline{\mathrm{x}} \pm \mathrm{SD}=20.2 \pm$ $7.91, n=5)$ on 28 March 2002 (Fig. 5). Newly deposited egg sacs were not found on 16 February or 27 March. The water velocity around stones with newly deposited egg sacs on 28 March had a range of $10.0-21.0 \mathrm{~cm} / \mathrm{sec}$ $(\overline{\mathrm{x}} \pm \mathrm{SD}=16.6 \pm 4.9, \mathrm{n}=5)$ (Fig. 5). There was no significant difference in velocity of surrounding water between stones with and without males (U-test: $\mathrm{z}=0.89, \mathrm{P}>0.1$ on 16 February; $\mathrm{z}=0.74, \mathrm{P}>0.1$ on 27 March; $\mathrm{z}=1.06, \mathrm{P}>0.1$, on 28 March); between stones with and without newly deposited egg sacs on 28 March $(\mathrm{z}=-0.51, \mathrm{P}>0.5)$; or between stones with males and with egg sacs on $28 \operatorname{March}(z=1.04$, $\mathrm{P}>0.1$. 

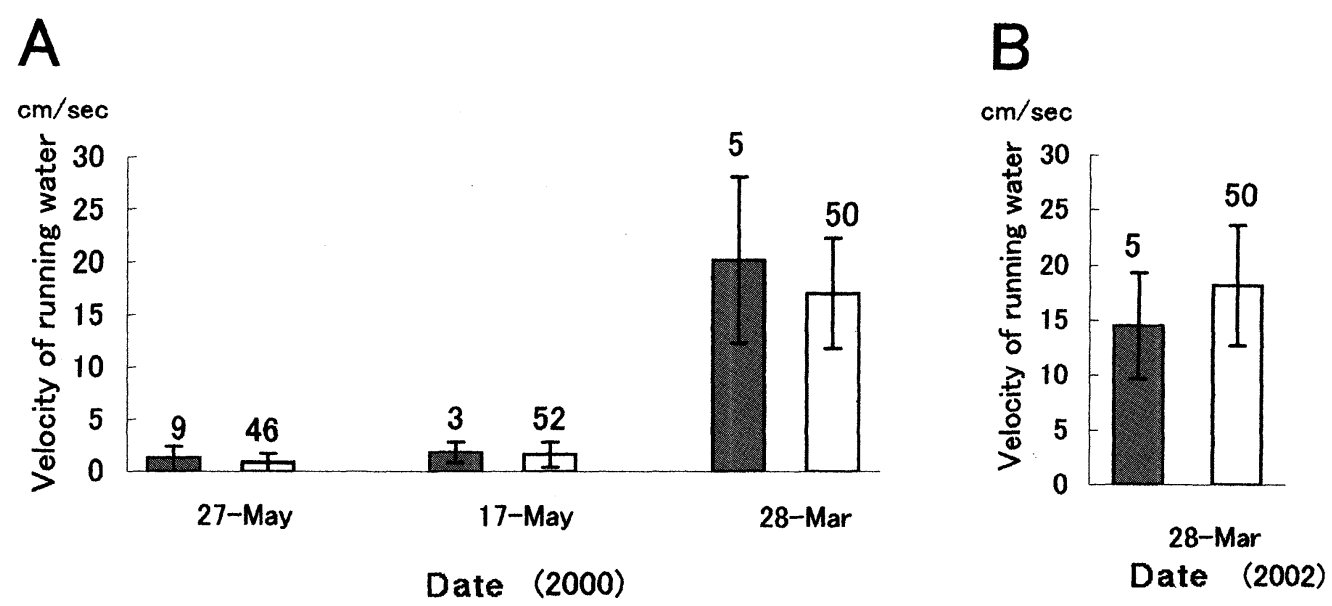

FIG. 5. Mean velocity of running water around stones with (filled squares) and without (open squares) males (A) and egg sac pairs (B). Vertical bars indicate ranges of standard deviations from means. Numerals above bars denote sample size.

Stone size selection by salamanders

Selectivity for broad stones by females tested by bootstrapping was statistically significant in $2000(\mathrm{P}<0.05)$, but not in $2002(\mathrm{P}>0.05)$.

\section{The number of egg sacs washed away}

There were no egg sacs washed away after the rainfall on 17 and 27 February or on 6 and 27 March 2002 despite a prominent rise in the stream water level at those times.

\section{The number of males per stone}

Most stones with males were occupied by single males. The only exceptions were two stones which each had two males underneath on 22 March 2000 and 16 February 2002. Except for these cases, observed frequency of stones with single males always exceeded expected values (Table 1).

\section{DISCUSSION}

Kusano and Kawakami (1999) argued that H. tokyoensis prefers to breed in shallow waters of small ponds or puddles to avoid aquatic predators, such as fishes, that require deeper water for their habitats. This may explain why this salamander breeds in the present stream, where the water depth remains shallow even after a rainfall.
The hollows used for breeding exhibited several common features, such as coverage by relatively broad stones, and locations in relatively deep positions in the stream. This suggests that the salamanders select particular hollows over the others for spawning to avoid accidental washing away of egg sacs from hollows, although the results of bootstrapping for data from 2002 failed to support selection of broader stones by females. Results of the bootstrap in 2002 may be attributable to a shortage of available hollows under broad stones due to accumulation of mud washed down from the hill in this and previous years (see above).

There were no egg sacs actually washed away during study period in 2002. This may reflect the effectiveness of depositing egg sacs under broad stones to avoid their being washed away.

Water depth of hollows used by the salamanders was significantly greater than that of unused hollows. This seems to contradict the data of Kusano and Kawakami (1999), which suggest a possible preference of the salamanders for shallower sites for spawning. Further work is needed to come to a conclusion on this issue.

In the stream, the frequency of stones with only a single male almost consistently exceeded 


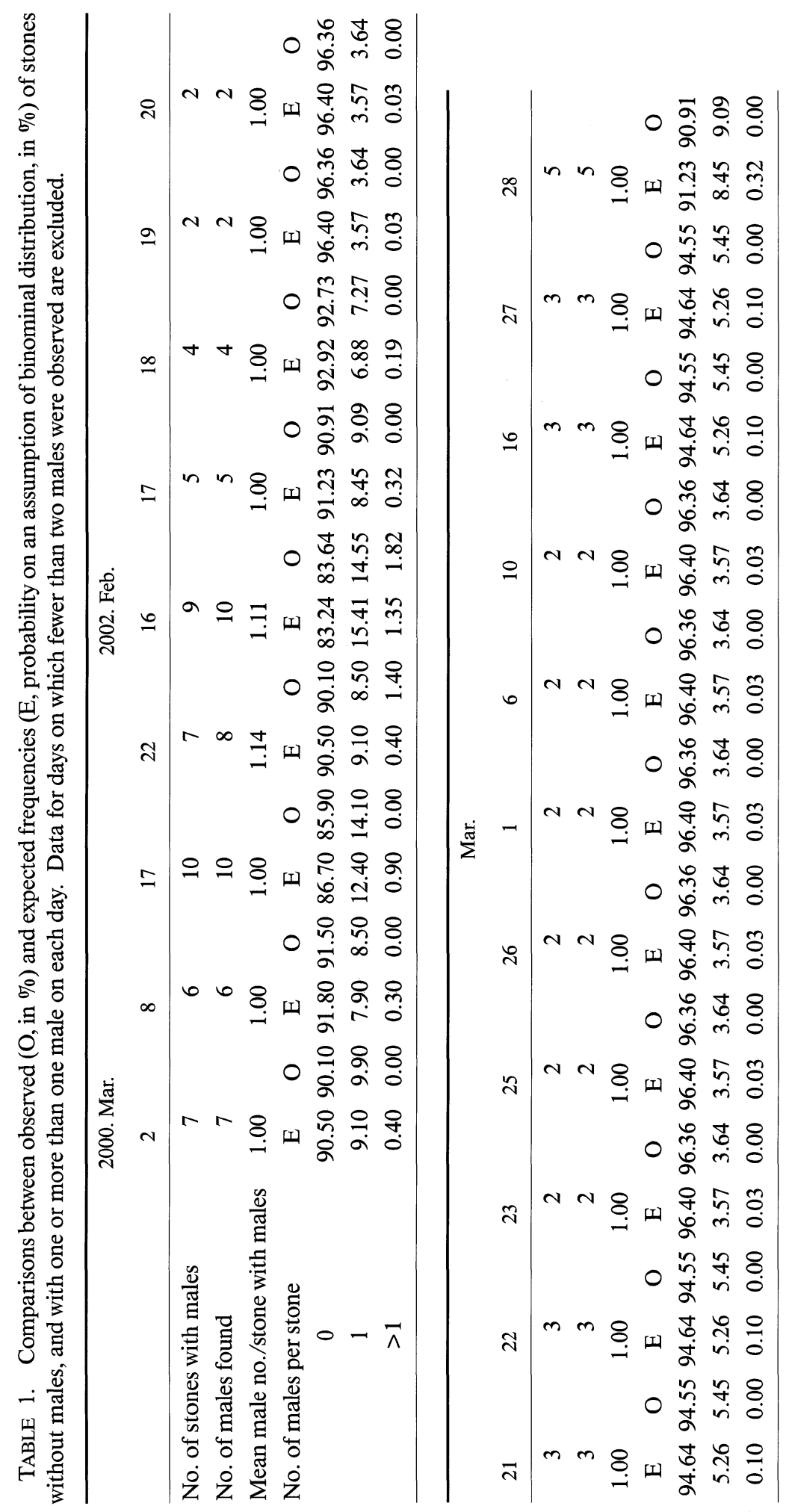


the expected value. This strongly suggests that the males prefer to stay alone. Kusano and Kawakami (1999) reported that males of this salamander in ponds aggressively guarded from other males particular sites that were seemingly suitable for spawning. It is likely that in the present stream males guarded their hollows from others through aggressive interactions. Considering that the mean of areas of stones with males was consistently smaller than that of stones with egg sacs, such guarding of hollows under broader stones by males may lead to a form of sexual selection.

\section{ACKNOWLEDGMENTS}

I would like to thank Dr. Yasuchika Misawa for offering information on the study site, Dr. Tamotsu Kusano for his advice on various aspects of this project, and Mr. Yasuhiro Ooki and Dr. Beatriz Casareto for instruction regarding technical terms of hydrography.

\section{Literature Cited}

AKITA, Y. 2000. Choice of the spawning site in the salamander, Hynobius nigrescens. Amphib. Hist. 4: 13-17. (in Japanese)

DuELlMAN, W. E. AND L. TRUEB. 1986. Biology of Amphibians. McGraw-Hill, Inc., New York. 670 p.

KAKEGAWA, M., K. IIZUKA, AND S. KUZUMI. 1989. Morphology of egg sacs and larvae just after hatching in Hynobius sonani and H. formosanus from Taiwan, with an analysis of skeletal muscle protein compositions. p. 147-155. In: M. Matui, T. Hikida, and R. C. Goris (eds.), Current Herpetology in East Asia. Herpetological Society of Japan, Kyoto.

KANEDA, M. AND M. OHNO. 1998. Distribution and abundance of Hynobius tokyoensis (Urodela: Hynobiidae) in Kanagawa Prefecture. Nat. Hist.
Rep. Kanagawa (19): 1-4. (in Japanese)

KuSANO, T. AND K. MiYASHITA. 1984. Dispersal of the salamander, Hynobius nebulosus tokyoensis. J. Herpetol. 18(4): 349-353.

KUSANO, T. AND Y. KAWAKAMI. 1999. Does Hynobius tokyoensis survive? Workshop on the Biology and Conservation of Hynobius tokyoensis. Privately Published, Tokyo. 69 p. (in Japanese)

MANLY, B. F. J. 1997. Randomization, Bootstrap and Monte Carlo Methods in Biology. Chapman and Hall, London. 399 p.

Petranka, J. W. 1998. Salamanders of the United States and Canada. Smithsonian Institute Press, Washington and London. $587 \mathrm{p}$.

SATO, I. 1943. A Monograph of the Tailed Batrachians of Japan. Nippon Shuppan-Sha, Osaka. 520 p. (in Japanese)

SATO, T. 1989. Breeding environment and spawning of a salamander Hynobius retardatus, at the foot of Hidaka Mountains, Hokkaido, Japan. p. 292-304. In: M. Matui, T. Hikida, and R. C. Goris (eds.), Current Herpetology in East Asia. Herpetological Society of Japan, Kyoto.

ShibATA, T. 1973. Amphibians of the Miura Peninsula. Sci. Rep. Yokosuka City Mus. 20: 1117. (in Japanese)

Stebiins, R. C. AND N. W. COHEN. 1995. A Natural History of Amphibians. Princeton University Press, Princeton and New Jersey. 316 p.

TANAKA, K. 1992. The choice of male territorial areas and female spawning site in Hynobius nebulosus II. The experiments by the devices. Jpn. J. Herpetol. 14 (4): 147. (Abstract, in Japanese)

UMESAO, T. 1949. Social interface between individuals-Its concept and experiments. Biol. Sci. (Tokyo) 1(1): 19-29. (in Japanese)

Accepted: 30 December 2002 